\title{
EDITORIAL
}

\section{In Memory of Paul J. Lioy, PhD, Deputy Editor of JESEE}

Journal of Exposure Science and Environmental Epidemiology (2015) 25, 543; doi:10.1038/jes.2015.53; published online 2 September 2015

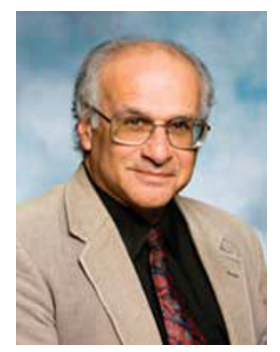

I regret to inform our readers of the unexpected passing of our colleague and friend Paul Lioy on 8 July 2015, at the too-young age of 68. Paul and I were in a small group that worked to establish the International Society of Exposure Assessment (ISEA) in 1990, which later became the International Society of Exposure Science (ISES). The journal sponsored by the Society is the Journal of Exposure Science and Environmental Epidemiology. Paul was the first elected President of ISEA.

At the time of his death Paul was a professor of environmental and occupational health at the Rutgers University School of Public Health, in Piscataway, NJ. He was also the deputy director for government relations at the school and at the university's Environmental and Occupational Health Science Institute (EOHSI).

I first met Paul in 1975, when we became members of a research consortium that planned and conducted the New York Summer Aerosol Study. ${ }^{1}$ It was a very unusual undertaking, with each of the lead investigators taking part in simultaneous, comprehensive, and complementary field-based studies of pollutant concentrations and regional transport in the Greater New York region. Amazingly, it encompassed six groups of investigators, with each group relying solely on its own air pollution research funding. Paul Lioy and George Wolff were the lead investigators from the Interstate Sanitation Commission (New York and New Jersey).

I was able to recruit Paul to join the New York University (NYU) research team in 1978, and he helped me launch a pioneering series of studies of the effects of ambient air pollution on respiratory function in children and adults engaged in outdoor recreation. These studies demonstrated significant reductions in inspiratory flow rates at much lower ozone concentrations than those reported for children and adults in controlled chamber exposures. While at NYU, he became a member of the American Conference of Governmental Industrial Hygienists (ACGIH) and its technical committees on air-sampling instruments and airsampling procedures, both of which he chaired. Paul was the coeditor with his wife Jean, of the sixth edition (1983) of the ACGIH's reference book Air Sampling Instruments for Evaluation of Atmospheric Contaminants. In addition to ISES and ACGIH, Paul was a longtime member of: the Air Pollution Control Association and its successor, the Air and Waste Management Association (AWMA); the International Society of Environmental Epidemiology; and the American Association for Aerosol Research. He also served as a chair and/or member of numerous external scientific advisory committees for the National Research Council, the Environmental Protection Agency's Science Advisory Board; Consumer Products Safety Commission, the Harvard School of Public Health, the University of Pittsburgh Medical Center and its School of Public Health, and numerous agencies of the government of the State of New Jersey.

In 1985, Paul joined the newly recruited faculty of the EOSHI in Piscataway, NJ, where he rapidly built an outstanding and highly productive research team and created the first academic doctoral training program that focused on human exposure science. Its graduates are now emerging leaders in the field. At Rutgers, Paul was research advisor to 25 doctoral and 9 postdoctoral trainees.

Paul was an author or coauthor of 285 peer-reviewed publications and 8 books, including the following three recent publications: Dust: The Inside Story of Its Role in the September 11th Aftermath (2010, Roman and Littlefield); 'Exposure Science to Protect Children's Health,' coauthored with C.P. Weisel, a chapter in Textbook of Children's Environmental Health (2013, Oxford University Press); and Exposure Science: Basic Principles and Applications, coauthored with C.P. Weisel (2014, Elsevier).

For his exceptional personal accomplishments as a scientist, Paul received the Jerome Wesolowski Award for Lifetime Excellence in Exposure Assessment Research from ISES in 1998, the Frank A. Chambers Award for outstanding achievement in the science and art of air pollution control from AWMA in 2003, and the annual Rutgers Graduate School Alumni Award in 2008.

Paul became the Deputy Editor-in-Chief of JESEE in 2013, with the understanding that he would be the next Editor-in-Chief when he was closer to retirement from his full-time position at Rutgers. It will be difficult to find one as experienced and knowledgeable as Paul.

\section{CONFLICT OF INTEREST}

The authors declare no conflict of interest.

Morton Lippmann

Department of Environmental Medicine, NYU Langone Medical

Center, Tuxedo, NY, USA

E-mail: morton.lippmann@nyumc.org

\section{REFERENCES}

1 Leaderer BP, Bernstein DM, Daisey JM, Kleinman MT, Kneip TJ, Knutson EO et al. Summary of the New York summer aerosol study (NYSAS). J Air Pollut Cont Assoc 1978; 28: 321-327. 